\title{
Recurrence of primary spontaneous pneumothorax following bullectomy with pleurodesis or pleurectomy: A retrospective analysis
}

\author{
Shawn Brophy ${ }^{1}$, Kelly Brennan ${ }^{2}$, Daniel French ${ }^{3}$ \\ ${ }^{1}$ Division of General Surgery, Department of Surgery, Dalhousie University, Queen Elizabeth II Hospital - Victoria Campus, Halifax, NS, Canada; \\ ${ }^{2}$ Dalhousie Medical School, Department of Surgery, Dalhousie University, Queen Elizabeth II Hospital - Victoria Campus, Halifax, NS, Canada; \\ ${ }^{3}$ Division of Thoracic Surgery, Department of Surgery, Dalhousie University, Queen Elizabeth II Hospital - Victoria Campus, Halifax, NS, Canada \\ Contributions: (I) Conception and design: All authors; (II) Administrative support: D French; (III) Provision of study materials or patients: D French; \\ (IV) Collection and assembly of data: S Brophy; (V) Data analysis and interpretation: K Brennan; (VI) Manuscript writing: All authors; (VII) Final \\ approval of manuscript: All authors. \\ Correspondence to: Shawn Brophy, MD. Division of General Surgery, Dalhousie University, Queen Elizabeth II Hospital - Victoria Campus, 1276 \\ South Park Street, Halifax, NS, Canada. Email: shawn.brophy@dal.ca.
}

Background: Primary spontaneous pneumothorax is managed initially with observation and chest tube placement, followed by surgical intervention in select cases. With little currently published evidence, the role of surgical pleurodesis or pleurectomy to reduce primary spontaneous pneumothorax recurrence is unclear. This study compares the recurrence rates of primary spontaneous pneumothorax following bullectomy alone versus bullectomy with pleurodesis or pleurectomy.

Methods: A retrospective review was performed at a quaternary hospital for all patients undergoing surgery for primary spontaneous pneumothorax between June 2006 and December 2018. Patient demographics, disease severity, operative technique, and time between initial surgery and recurrence were recorded. Standard statistical techniques were used for univariable and multivariable analyses.

Results: Of 222 total included patients, 28 required a second surgery: 4 (1.8\%) for prolonged air leak and $24(10.8 \%)$ for recurrent pneumothorax. The median time from first to second surgery was 363 days and $35.7 \%$ of recurrences did not present until after two years. Age, sex, smoking, year of initial surgery, disease severity, and surgical technique did not significantly affect recurrence rate on univariable analysis. On multivariable analysis, the odds ratios of recurrence for bullectomy with mechanical pleurodesis or pleurectomy were respectively 0.82 and $0.15(\mathrm{P}=0.218)$, compared to bullectomy alone. Combined bullectomy, pleurectomy, and pleurodesis was most effective $(0 / 18,0 \%)$.

Conclusions: Bullectomy with pleurectomy and pleurodesis demonstrated a $0 \%$ recurrence rate for the treatment of primary spontaneous pneumothorax in this study. Statistical significance was not achieved in univariable or multivariable analyses comparing recurrence rates for the surgical approaches. A multi-center randomized controlled trial with longer follow-up than previously performed is needed to confirm these preliminary findings and optimize surgical management of primary spontaneous pneumothorax.

Keywords: Pneumothorax; video-assisted thoracic surgery (VATS); benign lung surgery; pleurectomy; pleurodesis

Submitted Nov 09, 2020. Accepted for publication Jan 20, 2021.

doi: $10.21037 /$ jtd-20-3257

View this article at: http://dx.doi.org/10.21037/jtd-20-3257 


\section{Introduction}

A pneumothorax forms when air collects in the pleural space between the lung and the chest wall. A nonspontaneous pneumothorax has an identifiable inciting event, most often being traumatic or iatrogenic. A spontaneous pneumothorax occurs despite having no readily identifiable inciting event. A primary spontaneous pneumothorax (PSP) occurs in a patient with no apparent underlying lung disease. PSPs are typically caused by rupture of subpleural blebs $(<2 \mathrm{~cm})$ or bullae $(\geq 2 \mathrm{~cm})(1)$.

PSP has an annual incidence of $18-28$ per 100,000 in men and 1.2-6.0 per 100,000 in women (2). The goals of treating a PSP include elimination of the existing pneumothorax and minimizing recurrence $(3,4)$. The most recent guidelines for management of PSP were published by The American College of Chest Physicians (ACCP) in 2001 and the British Thoracic Society (BTS) in $2010(5,6)$. In summary, small PSPs in stable patients can be observed but a large pneumothorax (variably defined in the guidelines as $>2$ or $>3 \mathrm{~cm}$ ) or any pneumothorax in an unstable patient requires aspiration or a chest tube. Chest tubes can be removed once there is no air leak. In these guidelines, if the air leak persists for more than approximately 4 days, the next recommended step is surgery. Previous studies have examined trials of non-operative management ranging from 3 to 14 days (7-9). The risk of recurrence for PSPs treated with conservative treatment alone is $16-52 \%$ after the first episode and $65 \%$ after the second ipsilateral episode $(10,11)$. Therefore, it is important to determine which surgical technique best minimizes recurrence risk.

The standard surgical approach for management of PSP is bullectomy. Classically, congenital bullae exist in the apex of the lung and wedge resection of the portion of lung containing these ruptured bullae (bullectomy) will decrease the risk of pneumothorax recurrence. In addition to bullectomy, pleurectomy or pleurodesis is performed to further decrease the risk of pneumothorax recurrence. However, there is limited data suggesting that these additional procedures offer benefit. Specifically, studies have been published showing no further decrease in pneumothorax recurrence risk following bullectomy with mechanical pleurodesis (12), chemical pleurodesis (13), or pleurectomy (14) compared to bullectomy alone. These studies are criticized for having relatively short followup periods (mean 18-46 months). There is currently no consensus guideline on the surgical approach which best minimizes pneumothorax recurrence risk and despite a lack of evidence, pleurodesis or pleurectomy are still commonly performed with bullectomy in patients thought to have a high recurrence risk (6). To address existing gaps in the literature, this study's primary objective is to examine recurrence rates when pleurodesis or pleurectomy is performed with bullectomy compared to bullectomy alone in patients with PSP. We hypothesize that patients who undergo bullectomy with pleurodesis or pleurectomy will have a decreased recurrence rate compared to patients who undergo bullectomy alone. Secondary objectives include an evaluation of patient and disease factors associated with recurrence. We present the following article in accordance with the STROBE reporting checklist (15) (available at http://dx.doi.org/10.21037/jtd-20-3257).

\section{Methods}

\section{Study design and population}

This retrospective cohort study describes patient outcomes after surgical treatment for PSP at a quaternary-care hospital for the region and the only center providing thoracic surgery services. All incident cases of PSP treated with bullectomy from June 2006 to December 2018 in patients older than 17 and younger than 45 years of age were identified using the Canadian Institute for Health Information (CIHI) hospitalization records. Comparable publications limited the upper age limit for inclusion at 40 years $(12,14)$ or 50 years $(13)$. Chart abstraction for patient demographics and operative details was completed using electronically available medical records.

The study was conducted in accordance with the Declaration of Helsinki (as revised in 2013). The study was approved by the institutional ethics board of the Nova Scotia Health Authority (File number 1024736) and individual consent for this retrospective analysis was waived.

\section{Measures and outcomes}

The primary study outcome is pneumothorax recurrence. Recurrence was defined to occur in a participant who had already undergone bullectomy or wedge resection for PSP requiring a second surgery for ipsilateral pneumothorax either for prolonged air leak or from true recurrence. If this second surgery occurred fewer than 15 days after the initial surgery date, this was classified as a prolonged air leak. If a second surgery was performed more than 15 days following the initial surgery, it was classified a 'true' recurrent 


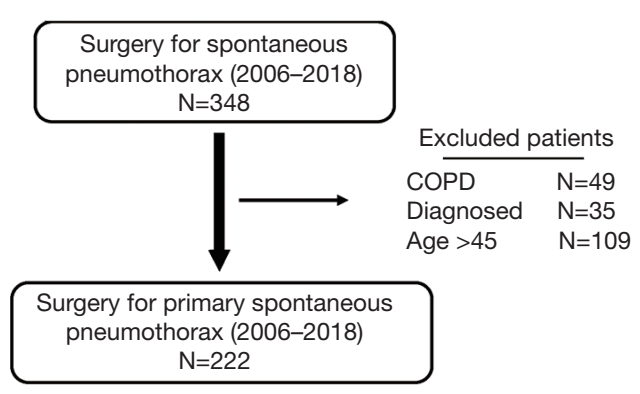

Figure 1 CONSORT diagram of study population identification

pneumothorax. The etiology of the clinical recurrence in each case was not captured in the original data which is why 'true recurrence' and 'prolonged air leak' are defined temporally. The cut-off of 15 days was chosen because at our centre, no patient would undergo a trial of inpatient non-operative management of an air leak exceeding 15 days, and comparable previous studies have examined trials of non-operative air leak management ranging from 3 to 14 days (7-9). There were no instances in which a patient presented following bullectomy with a clinical or radiographic ipsilateral pneumothorax recurrence and was managed non-operatively rather than undergoing a second ipsilateral surgery.

Secondary outcomes included an assessment of potential predictors of pneumothorax recurrence. These factors included age, sex, smoking status, disease severity, surgical method, contralateral pneumothorax (historical diagnosis or diagnosed during the study period), year of initial surgery, surgical approach, and performance of decortication. A priori the cases were stratified based on an assessment of disease severity. Disease severity was scored based on thoracoscopic findings at the time of surgery using Vanderschueren's classification (14). In this validated classification scheme, stage 1 is used when no thoracoscopic abnormalities are noted, stage 2 when pleuropulmonary adhesions are seen, stage 3 when blebs are noted with a greatest dimension $<2 \mathrm{~cm}$, and stage 4 when bullae with a greatest dimension $\geq 2 \mathrm{~cm}$ are noted. Some operative dictations did not explicitly measure the greatest dimension of the bullae seen. In these cases, bullae described as 'giant,' or 'large' were categorized as stage 4 , and blebs described as 'small' were categorized as stage 3 . In cases for which the operative note did not adequately describe bulla size, the pathology report was used to estimate size. Those cases for which disease severity could not be determined based on the operative or pathology reports are reported as
'Indeterminate'.

Pleurectomy was defined as the removal of the parietal pleura. The typical method of pleurectomy in this study involved using electrosurgery to circumferentially delineate a section of parietal pleural, and then peeling this pleura from the underlying structures. Mechanical pleurodesis was defined as abrasion of the parietal pleura and was typically performed by inserting a small piece of cautery scratch pad into the pleural space and using it to scratch the parietal pleura. Chemical pleurodesis is not commonly used in the operating room at this institution. Decortication was defined broadly in this study as peeling off a visceral pleural rind and/or extensive lysis of intrathoracic adhesions. The group called 'Any Pleurectomy' includes patients who had a partial pleurectomy in addition to some form of mechanical and/or chemical pleurodesis.

Patients in this study typically had one scheduled follow-up appointment approximately 4 to 6 weeks postoperatively. Beyond this one scheduled appointment, the patient was brought to the attention of the Thoracic Surgery group if they experienced symptoms and then underwent a chest $\mathrm{X}$-ray demonstrating pneumothorax recurrence. In this catchment area, Thoracic Surgery is performed only at this quaternary centre, so pneumothorax recurrences would not be referred elsewhere.

\section{Statistical analysis}

Comparisons of proportions between study groups were made using the Chi-square tests and Fisher's exact tests when cell sizes were less than five. $T$-tests were used to analyze continuous variables. Factors associated with recurrence were evaluated by logistic regression. Results were considered statistically significant at $\mathrm{P}$ value $<0.05$. All analyses were performed using SAS version 9.4 (SAS Institute, Cary, NC). To account for the time to the outcomes, we additionally re-examined our data using the Kaplan-Meier method with log-rank tests for univariable analysis and Cox regression for multivariable analysis.

\section{Results}

Two hundred and twenty-two patients were included in the study (Figure 1). Thirteen percent (28/222) were operated on for pneumothorax recurrence (Table 1). The median age was 24 years (IQR 19-32) and 73\% (161/222) of patients were male. Thirty-seven percent (82/222) of patients smoked tobacco and $16 \%(36 / 222)$ had a history 
Table 1 Characteristics of study population

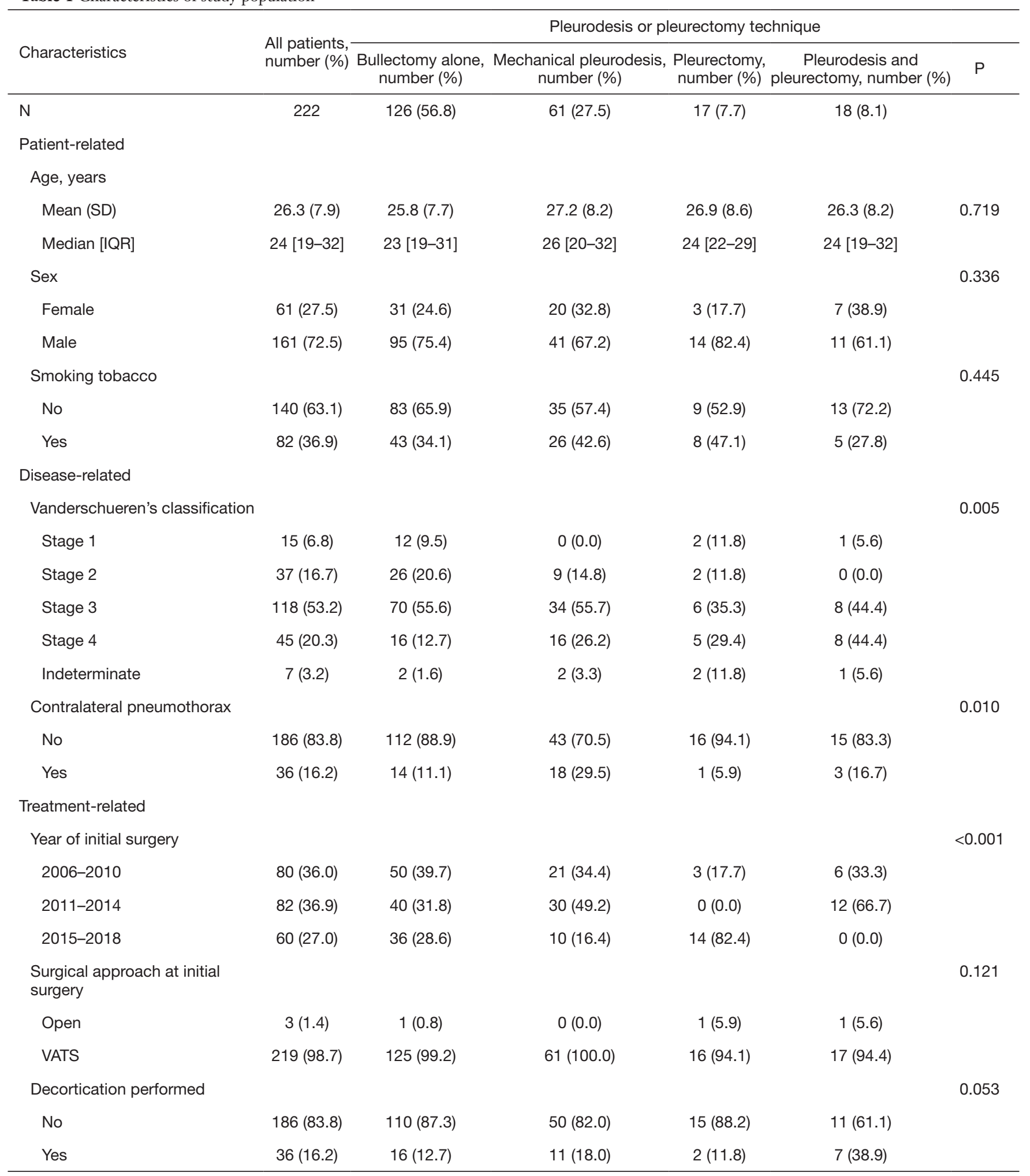

Table 1 (continued) 
Table 1 (continued)

\begin{tabular}{|c|c|c|c|c|c|c|}
\hline \multirow[b]{2}{*}{ Characteristics } & \multirow{2}{*}{$\begin{array}{l}\text { All patients, } \\
\text { number (\%) }\end{array}$} & \multicolumn{5}{|c|}{ Pleurodesis or pleurectomy technique } \\
\hline & & $\begin{array}{c}\text { Bullectomy alone, } \\
\text { number }(\%)\end{array}$ & $\begin{array}{c}\text { Mechanical pleurodesis, } \\
\text { number }(\%)\end{array}$ & $\begin{array}{c}\text { Pleurectomy, } \\
\text { number (\%) }\end{array}$ & $\begin{array}{c}\text { Pleurodesis and } \\
\text { pleurectomy, number (\%) }\end{array}$ & $P$ \\
\hline No & $194(87.4)$ & 107 (84.9) & $53(86.9)$ & $16(94.1)$ & $18(100.0)$ & \\
\hline Yes & $28(12.6)$ & $19(15.1)$ & $8(13.1)$ & $1(5.9)$ & $0(0.0)$ & \\
\hline
\end{tabular}

In all patients bullectomy was performed, and pleurectomy or pleurodesis were performed in addition at the time of bullectomy. Vanderschueren's classification: stage 1, no noted thoracoscopic abnormalities; stage 2, pleuropulmonary adhesions; stage 3, largest defect present is a subpleural bleb $(<2 \mathrm{~cm}$ in greatest dimension); stage 4 , largest defect present is a subpleural bulla ( $\geq 2 \mathrm{~cm}$ in greatest dimension). SD, standard deviation; IQR, inter-quartile range.

Table 2 Time between first and second surgery

\begin{tabular}{|c|c|c|c|c|c|}
\hline & $\begin{array}{l}\text { Patients with } \\
\text { recurrence }\end{array}$ & $\begin{array}{l}\text { Bullectomy } \\
\text { alone }\end{array}$ & $\begin{array}{l}\text { Mechanical } \\
\text { pleurodesis }\end{array}$ & Pleurectomy & $\begin{array}{l}\text { Pleurodesis and } \\
\text { pleurectomy }\end{array}$ \\
\hline $\mathrm{N}$ & 28 & 19 & 8 & 1 & 0 \\
\hline \multicolumn{6}{|c|}{ Days between first and second surgery } \\
\hline Mean (SD) & $700.3(921.7)$ & $523.3(538.3)$ & $1,208.0(1,443.1)$ & - & - \\
\hline
\end{tabular}

of a contralateral pneumothorax. Decortication was necessary in $16 \%$ (36/222) of initial surgeries and only three (1\%) required an open thoracotomy rather than a VATS approach.

The pleurectomy and pleurodesis groups were statistically similar with four notable exceptions. For patients undergoing both mechanical pleurodesis and pleurectomy, significantly more had Vanderschueren's stage 4 disease $(44 \%, 8 / 18)$, and no patients had disease stage $2(\mathrm{P}=0.005)$. For the mechanical pleurodesis group, significantly more patients had a documented contralateral pneumothorax than in the other groups $(30 \%, 18 / 61$, $\mathrm{P}=0.010)$. No patients from the pleurectomy group had surgery performed from 2011-2014 and no patients in the group combining pleurectomy with some form of pleurodesis had surgery from 2015-2018 ( $\mathrm{P}<0.001)$. Finally, decortication was performed in significantly more patients undergoing both mechanical pleurodesis and pleurectomy than for the other treatment groups $(39 \%, 7 / 18, \mathrm{P}=0.053)$.

The overall population recurrence rate for PSP treated with surgery was $13 \%(28 / 222)$. When analyzed based on operative technique, the overall recurrence rate for bullectomy alone was 15\% (19/126) and for bullectomy plus any form of pleurodesis, the recurrence rate was $9 \%(9 / 96$,
$\mathrm{P}=0.205)$. When examined by specific surgical approaches, bullectomy plus mechanical pleurodesis was $13 \%(8 / 61)$, bullectomy plus pleurectomy was $6 \%(1 / 17)$, and for bullectomy plus pleurectomy and mechanical pleurodesis the recurrence rate was $0 \%(0 / 18, \mathrm{P}=0.302)$.

For the 28 patients who went on to have a second surgery for PSP, the median time from initial surgery to second surgery for recurrence was 363 days (IQR 20-1,026, Table 2). The distribution of recurrences based on number of days between the first surgery for PSP and the second surgery for recurrence is presented in Figure 2. Four (14\%) patients had a second surgery within the first 15 days following the initial surgery due to prolonged air leaks. Between 16 and 30 days following the initial surgery, $6(21 \%)$ patients had a second surgery for a recurrent PSP. Between a month and a year following the initial surgery, $4(14 \%)$ were operated on for recurrence. Between one and two years following the initial surgery, 4 (14\%) required reoperation, and between two and three years an additional four required surgery for a recurrence. Six $(21 \%)$ patients required re-operation to treat a recurrence at more than three years following their initial surgery, with the longest duration between first and second surgery being 10 years (3,652 days). Nine patients had three or more surgeries. 


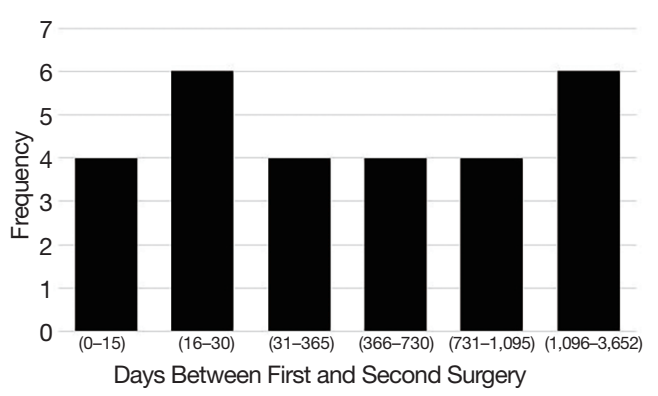

Figure 2 Frequency of cases of recurrence.

Seven out of the nine had more than two surgeries due to contralateral pneumothorax and two patients $(2 / 9 ; 22 \%)$ had three surgeries due to a second ipsilateral recurrence.

Univariable and multivariable analyses (Table 3) found no associations between rate of recurrence and year of surgery, age, sex, smoking, or disease severity. On multivariable analysis using PSP treated with bullectomy alone at the time of initial surgery as a reference, patients who underwent bullectomy with mechanical pleurodesis at the time of initial surgery were found to have a lower risk of recurrence (OR 0.82, 95\% CI: 0.31-2.20) and those who underwent bullectomy with any pleurectomy were found to have the lowest risk of recurrence, though these differences were not statistically significant (OR 0.15, 95\% CI: 0.02-1.27, $\mathrm{P}=0.218)$. There were no differences in the results when reexamined using time to event analysis.

\section{Discussion}

The recurrence risk in this study for patients treated for PSP with bullectomy and pleurectomy trended lower than for patients treated with bullectomy alone, although this difference was not statistically significant. Notably, none of the 18 patients treated with bullectomy, pleurectomy, and pleurodesis experienced recurrence. Interpreting these findings is challenging because we were unable to include a zero value in our analysis. Presumably the true recurrence rate for this group is nonzero and a study containing more participants may have been able to statistically analyze this nonzero recurrence rate. Any significant difference in recurrence rates would contrast with the findings of earlier studies, which found no such effect (12-14).

The recurrence rates in this study are higher than previously reported. Recurrence was $15 \%$ for PSP treated with bullectomy alone, $13 \%$ for those treated with bullectomy and mechanical pleurodesis, and 6\% for PSP treated with bullectomy and pleurectomy (with or without additional pleurodesis, Table 3). In a 2014 RCT by Min et al., recurrence following bullectomy alone was $7.5 \%$ and for bullectomy with mechanical pleurodesis was $5.9 \%$ (12). In a 2008 RCT by Rena et al., recurrence following bullectomy with apical pleurectomy was $4.6 \%$ and for bullectomy with mechanical pleurodesis was $6.2 \%$ (14). It is possible that follow-up in these earlier studies was too short to accurately capture the true recurrence rate. The mean follow-up for Min et al. was 18 months (range 6 to 24 months), and for Rena et al. was 46 months (range 24 to 66 months) $(12,14)$. The median follow-up in the present study was 81 months (range 12 to 162 months) and $35.7 \%$ of the recurrences were recorded more than 3 years following the initial surgery (Figure 2). One recurrence was noted 10 years following the initial surgery. Followup periods for previous studies may be inadequately short, potentially missing a significant number of recurrences.

A recent meta-analysis found that the addition of chemical pleurodesis to VATS mechanical pleurodesis or pleurectomy with or without bullectomy was associated with a $63 \%$ lower risk of pneumothorax recurrence compared to intervention without chemical pleurodesis (16). Our institution tends not to use chemical pleurodesis as a first line agent in cases of pneumothorax recurrence and the chemical agents used in this meta-analysis were heterogeneous (variably minocycline, tetracycline, talc, and dextrose), so these results aren't comparable to our data. However, there may additionally be a role for chemical pleurodesis to further minimize recurrence risk of PSP.

No statistically significant association was found between recurrence rate and any other factors analyzed in this study. This lack of associations contrasts with previously published studies. Predictors of increased recurrence rate after surgery for PSP have previously been identified for smoking $(17,18)$, younger age $(19,20)$, female sex $(17,18)$, VATS approach (21), and greater disease severity (14).

Although not statistically significant, patients found to have no thoracoscopic abnormalities (Vanderschueren's stage 1) were more likely to recur than were patients found to have a lesion. Review of the operative reports revealed that following an initial surgery which failed to find a thoracoscopic abnormality, blebs or bullae were found in many of the second surgeries. It is possible that these lesions were missed initially. It is important to maintain a high suspicion that a targetable bulla is present even when no thoracoscopic abnormality is initially discovered. Tsou et al. found no association 
Table 3 Univariable and multivariable analyses

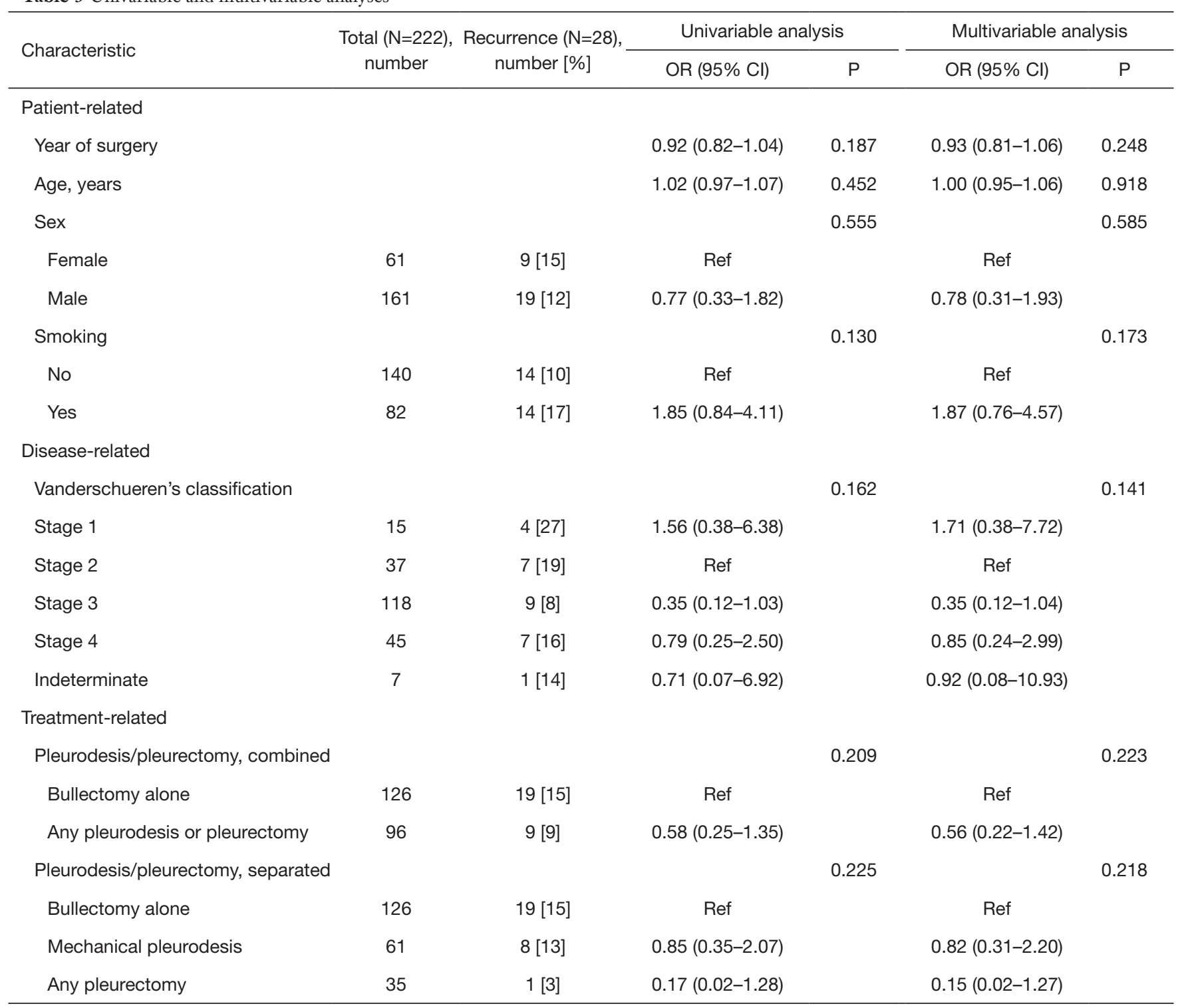

In all cases bullectomy was performed, and pleurectomy or pleurodesis were performed in addition at the time of bullectomy. Of 222 in the total population, 28 patients were operated on a second time for recurrence. Vanderschueren's classification: stage 1, no noted thoracoscopic abnormalities; stage 2, pleuropulmonary adhesions; stage 3, largest defect present is a subpleural bleb $(<2 \mathrm{~cm}$ in greatest dimension); stage 4, largest defect present is a subpleural bulla ( $\geq 2 \mathrm{~cm}$ in greatest dimension).

between performance of a pre-operative CT scan of the chest in cases of PSP and recurrence after surgery (22). Additionally, bullae detection rates are recorded to be higher during surgery (76-100\%) than on pre-op CT scans (23-25). Almajid et al. reported a positive predictive value (PPV) of $86 \%$ and a negative predictive value (NPV) of $73 \%$ for detection of PSP on CT scan (26). Therefore, pre-operative CT scan does not seem to confer a superior rate of bulla detection and may not be helpful even in cases where no bullae are initially detected thoracoscopically. This recommendation against routine performance of chest CT scans is consistent with current guidelines $(6,27)$.

This study is population-based, thus avoiding the bias associated with more restricted cohorts and suffering very little loss to follow-up. The population is young (age $<45$ ) 
and few health-related confounders are thought to exist in this study. In addition to the limitations inherent to a retrospective study, selection bias may exist in this analysis because the type of surgery performed for each patient was unilaterally chosen by the surgeon. The authors predicted that a surgeon's decision about which procedure to perform may have been influenced by disease severity, which is why a priori the cases were stratified by disease severity. It is likely, however, that this stratification incompletely compensated for the selection bias. The cohort in this study was possibly too small to detect weaker associations despite the sample size being comparable to similar published studies (12-14). In comparison to the rest of Canada, the population of the Maritime provinces tends to be more rural, more Caucasian, and have a higher BMI (28-30). Despite these differences, the results of this study are generalizable to any North American population.

One limitation of this study is that we did not explicitly examine complications from the various surgical methods. Chen $e t a l$. reported on a similar population and looked at post-operative pain and chest tube drainage (13). In this study, patients reported greater pain following pleurectomy than following mechanical pleurodesis and chemical pleurodesis using minocycline on, but not following, the first post-operative day. Additionally, they report that the total chest tube drainage was significantly more following pleurectomy than following mechanical pleurodesis and chemical pleurodesis.

In summary, based on this retrospective observational analysis, no significant difference was found in the rate of recurrence of PSP treated with bullectomy and pleurectomy or bullectomy and pleurodesis. We were unable to properly assess the difference in recurrence between these rates and the rate for the bullectomy, pleurectomy, and pleurodesis group, because the recurrence rate for this group was zero. Performance of a combination of pleurectomy and mechanical pleurodesis with bullectomy may be indicated in cases of PSP suspected to be at higher risk of recurrence. A multi-centred randomized controlled trial (RCT) is necessary to further answer this question. Based on the temporal distribution of recurrences found in these data, the 2 to 3 -year follow-up used in most published pneumothorax-related RCTs to date is inadequate and should be extended to 5 years of follow-up to accurately capture the recurrence rate.

\section{Acknowledgments}

An early version of this project was presented at the
Dalhousie University Dept. of Surgery Research Symposium in Halifax, Nova Scotia, Canada, on June 3, 2020.

Funding: None.

\section{Footnote}

Reporting Checklist: The authors have completed the STROBE reporting checklist. Available at http://dx.doi. org/10.21037/jtd-20-3257

Data Sharing Statement: Available at http://dx.doi. org/10.21037/jtd-20-3257

Conflicts of Interest: All authors have completed the ICMJE uniform disclosure form (available at http://dx.doi. org/10.21037/jtd-20-3257). The authors have no conflicts of interest to declare.

Ethical Statement: The authors are accountable for all aspects of the work in ensuring that questions related to the accuracy or integrity of any part of the work are appropriately investigated and resolved. The study was conducted in accordance with the Declaration of Helsinki (as revised in 2013). The study was approved by the institutional ethics board of the Nova Scotia Health Authority (File number 1024736) and individual consent for this retrospective analysis was waived.

Open Access Statement: This is an Open Access article distributed in accordance with the Creative Commons Attribution-NonCommercial-NoDerivs 4.0 International License (CC BY-NC-ND 4.0), which permits the noncommercial replication and distribution of the article with the strict proviso that no changes or edits are made and the original work is properly cited (including links to both the formal publication through the relevant DOI and the license). See: https://creativecommons.org/licenses/by-nc-nd/4.0/.

\section{References}

1. de Hoyos A, Fry WA. Chapter 58: Pneumothorax. In: Shields TW, LoCicero J, Reed CE, Feins RH, eds. General Thoracic Surgery. 7th ed. Philadelphia: Lippincott Williams \& Wilkins; 2009:739-62.

2. Melton LJ, Hepper NG, Offord KP. Incidence of spontaneous pneumothorax in Olmsted County, Minnesota: 1950 to 1974. Am Rev Respir Dis 1979;120:1379-82.

3. Sahn SA, Heffner JE. Spontaneous Pneumothorax. N Engl 
J Med 2000;342:868-74.

4. Baumann MH, Strange C. Treatment of spontaneous pneumothorax: A more aggressive approach? Chest 1997;112:789-804.

5. Baumann MH, Strange C, Heffner JE, et al. Management of spontaneous pneumothorax: An American College of Chest Physicians Delphi consensus statement. Chest 2001;119:590-602.

6. MacDuff A, Arnold A, Harvey J. Management of spontaneous pneumothorax: British Thoracic Society pleural disease guideline 2010. Thorax 2010;65:ii18-ii31.

7. O'Rourke JP, Yee ES. Civilian spontaneous pneumothorax: Treatment options and long-term results. Chest 1989;96:1302-6.

8. Granke K, Fischer CR, Gago O, et al. The efficacy and timing of operative intervention for spontaneous pneumothorax. Ann Thorac Surg 1986;42:540-2.

9. Chee CBE, Abisheganaden J, Yeo JKS, et al. Persistent airleak in spontaneous pneumothorax: Clinical course and outcome. Respir Med 1998;92:757-61.

10. Baumann MH. Management of Spontaneous Pneumothorax. Clin Chest Med 2006;27:369-81.

11. Baumann MH. Do Blebs cause primary spontaneous pneumothorax? Pro: blebs do cause primary spontaneous pneumothorax. J Bronchol 2002;9:313-8.

12. Min X, Huang Y, Yang Y, et al. Mechanical pleurodesis does not reduce recurrence of spontaneous pneumothorax: A randomized trial. Ann Thorac Surg 2014;98:1790-6.

13. Chen JS, Hsu HH, Huang PM, et al. Thoracoscopic pleurodesis for primary spontaneous pneumothorax with high recurrence risk: A prospective randomized trial. Ann Surg 2012;255:440-5.

14. Rena O, Massera F, Papalia E, et al. Surgical pleurodesis for Vanderschueren's stage III primary spontaneous pneumothorax. Eur Respir J 2008;31:837-41.

15. von Elm E, Altman DG, Egger M, et al. STROBE Initiative: The Strengthening the Reporting of Observational Studies in Epidemiology (STROBE) statement: Guidelines for reporting observational studies. J Clin Epidemiol 2008;61:344-9.

16. Asban A, Raza SS, McLeod C, et al. Mechanical or chemical and mechanical pleurodesis for spontaneous pneumothorax: What is the most effective approach in preventing recurrence? A systematic review and metaanalysis. Eur J Cardiothorac Surg 2020;58:682-91.

17. Walker SP, Bibby AC, Halford P, et al. Recurrence rates in primary spontaneous pneumothorax: A systematic review and meta-analysis. Eur Respir J 2018;52:1-10.
18. Guo Y, Xie C, Rodriguez RM, et al. Factors related to recurrence of spontaneous pneumothorax. Respirology 2005;10:378-84.

19. Chikaishi Y, Kanayama M, Taira A, et al. What is the best treatment strategy for primary spontaneous pneumothorax? Ann Med Surg (Lond) 2019;45:98-101.

20. Asano H, Ohtsuka T, Noda Y, et al. Risk factors for reference of primary spontaneous pneumothorax after thoracoscopic surgery. J Thorac Dis 2019;11:1940-4.

21. Foroulis $\mathrm{CN}$. Surgery for primary spontaneous pneumothorax. J Thorac Dis 2016;8:E1743-5.

22. Tsou KC, Huang PM, Hsu HH, et al. Role of computed tomographic scanning prior to thoracoscopic surgery for primary spontaneous pneumothorax. J Formosan Med Assoc 2014;113:606-11.

23. Laituri CA, Valusek PA, Rivard DC, et al. The utility of computed tomography in the management of patients with spontaneous pneumothorax. J Pediatr Surg 2011;46:1523-5.

24. Lesur O, Delorme N, Fromaget JM, et al. Computed tomography in the etiologic assessment of idiopathic spontaneous pneumothorax. Chest 1990;98:341-7.

25. Sihoe AD, Yim AP, Lee TW, et al. Can CT scanning be used to select patients with unilateral primary spontaneous pneumothorax for bilateral surgery? Chest 2000;118:380-3.

26. Almajid FM, Aljehani YM, Alabkary S, et al. The accuracy of computed tomography in detecting surgically resectable blebs or bullae in primary spontaneous pneumothorax. Radiol Med 2019;124:833-7.

27. Tschopp JM, Bintcliffe O, Astoul P, et al. ERS task force statement: Diagnosis and treatment of primary spontaneous pneumothorax. Eur Respir J 2015;46:321-35.

28. Statistics Canada. Canada goes urban. Available online: https://www150.statcan.gc.ca/n1/pub/11-630-x/11-630x2015004-eng.htm. Accessed May 9, 2020.

29. Statistics Canada. Data tables, 2016 Census. Available online: https://www12.statcan. gc.ca/censusrecensement/2016/. Accessed May 9, 2020.

30. Statistics Canada. Health at a Glance. Available online: https://www150.statcan.gc.ca/n1/pub/82-624-x/2014001/ article/11922-eng.htm. Accessed May 9, 2020.

Cite this article as: Brophy S, Brennan K, French D. Recurrence of primary spontaneous pneumothorax following bullectomy with pleurodesis or pleurectomy: A retrospective analysis. J Thorac Dis 2021;13(3):1603-1611. doi: 10.21037/jtd-203257 